\title{
QUEM DECIDE SOBRE CONTROVÉRSIAS CIENTÍFICAS? UMA ANÁLISE DAS PERCEPÇÕES DE LICENCIANDOS EM CIÊNCIAS SOBRE PARTICIPAÇÃO SOCIAL E MODELOS DECISÓRIOS EM CIÊNCIA E TECNOLOGIA
}

\author{
Who Decides About Scientific Controversies? An Analysis about Science \\ Undergraduates' Beliefs on Citizen Participation and Decision Making Models
}

\begin{abstract}
Resumo: A complexidade de decisões públicas envolvendo ciência e tecnologia - C\&T é um desafio para a garantia de participação social em questões altamente especializadas. Em geral, a população reconhece a importância de regulações e controle social sobre $C \& T$. Mas como tal participação deve ocorrer? Modelos decisórios adotados para tais questões são indicadores da concepção de ciência e da necessidade de participação social no fechamento de controvérsias científicas. Com objetivo de compreender como licenciandos em ciências enxergam essas questões, o artigo propõe, através do emprego da análise textual discursiva, apresentar as percepções emergentes no discurso dos licenciandos de cursos de Biologia, Química e Física que participaram de um curso sobre as inter-relações ciência, tecnologia e sociedade. As categorias de análise foram duas: racionalidade científica e modelos decisórios. Os discursos emergentes deixam claro que o grupo separa controvérsias em dois grupos: as demasiado técnicas para que haja participação social, e as que envolvem questões morais mais pronunciadas, as quais deveriam acatar a participação social.
\end{abstract}

Palavras-chave: Formação docente. Controvérsias Científicas. Educação Científica.

\begin{abstract}
The complexity of public decisions involving science and technology - ST is a challenge for ensuring social participation. The population recognizes the importance of regulations and social control over ST. But how should such participation take place? Decision models are indicators of the conception of science and the need for social participation in closing scientific controversies. In order to understand how science undergraduates view these issues, the article proposes, through the use of discursive textual analysis, to present the emerging perceptions of Biology, Chemistry and Physics undergraduates who participated in a training about ST and society. The categories of analysis were scientific rationality and decision-making models. The emerging speeches make it clear that the group separates controversies into two groups: those that are too technical for social participation, and those that involve more pronounced moral issues, which should accept social participation.
\end{abstract}

Keywords: Teacher Training. Scientific Controversy. Scientific Education.

\footnotetext{
* Professora de Filosofia do Instituto Federal de Educação, Ciência e Tecnologia de Brasília, Campus Estrutural. Doutoranda em Política Científica e Tecnológica pela Universidade Estadual de Campinas; Mestra em Educação Profissional e Tecnológica pelo Instituto Federal de Goiás; Licenciada em Filosofia pela Universidade de Brasília. https://orcid.org/0000-0001-9528-7662. loryne@ymail.com.
} 


\section{Introdução}

Em 1986, Arthur Caplan, professor de Bioética na Universidade de Nova York, e Tristram Engelhardt, filósofo e professor na Universidade do Texas, escreveram no prefácio de um livro sobre controvérsias científicas que as sociedades contemporâneas levam a ciência a sério (CAPLAN, ENGELHARDT, 2003). Em 2017, Daniel Sarewitz, professor da Universidade do Arizona, dedicou um texto à reflexão sobre a necessidade de "salvar a ciência", que, segundo ele, estaria enfrentando, assim como outras instituições, uma crise profunda de credibilidade (SAREWITZ, 2017).

O interregno que torna díspar os posicionamentos de Caplan, Engelhardt e Sarewitz assistiu ao aumento significativo da difusão de disputas em ciência. Brewer (1973) atribui esta tendência ao fato de que, cada vez mais, cientistas são chamados para resolver uma ampla gama de questões políticas controversas envolvendo aspectos de ciência e tecnologia. Nelkin (1975), em seu canônico estudo sobre o envolvimento de cientistas em controvérsias, ao discutir o impacto da expertise técnica, afirma ser esta um recurso político que deve estar disponível para comunidades, corporações e desenvolvedores.

Uma consulta ao contexto nacional atual revela que metade da população concorda em manter cautela quanto à Ciência e Tecnologia - C\&T, expresso na concordância com assertivas indicadoras de percepção de risco, como "cientistas "têm poderes que os tornam perigosos"" (Centro de Gestão e Estudos Estratégicos - CGEE, 2019, p. 19). Uma grande maioria dos brasileiros se declara preocupada com temas de cunho técnico e científico. Desmatamento na Amazônia, uso de agrotóxicos na agricultura, mudanças climáticas e alimentos geneticamente modificados são exemplos de temas de interesse popular (CGEE, 2019). Ainda segundo o estudo, tal resultado desvela "uma preocupação com respeito à regulação da C\&T, a uma atenção aos aspectos éticos e a uma demanda por controle e participação social" (CGEE, 2019, p. 19).

Compreender a percepção pública sobre C\&T é de especial interesse para pesquisadores, gestores de políticas públicas, educadores, comunicadores e jornalistas - atores da chamada cultura científica (VOGT, 2003). Para tanto, é indispensável dispor de uma interpretação analítico-normativa das controvérsias científicas - palco das disputas e responsáveis pelo engajamento público e exercício cidadão no que diz respeito a aspectos da C\&T ligados ao desenvolvimento social e econômico (CGEE, 2019). Em outras palavras, controvérsias científicas representam indicadores de cidadania científica, e seu debate não pode prescindir de aprofundamento epistemológico e histórico.

Este empreendimento envolve todos os espaços de produção da pesquisa científica, de letramento científico-tecnológico, de popularização da ciência e de percepção pública da ciência, uma vez que, de acordo com Vogt (2003), o desenvolvimento científico é um processo cultural que engendra o estabelecimento de relações críticas e valores culturais por um cidadão em um tempo e em uma história.

Neste contexto, ganha especial destaque o papel do ensino de ciências enquanto articulador de transformações considerando os desafios impostos pelo século XXI: tomada de decisão informada, habilidade de analisar, sintetizar e avaliar informações, enfrentamento de questões morais e éticas, compreensão das conexões entre ciência, tecnologia e sociedade, compreensão da complexidade intrínseca às controvérsias científicas, cujo caráter social é inextirpável (ZEIDLER et al., 2005). Essa educação científica para os novos desafios se dá nos 
diversos níveis da espiral da cultura científica e deve ser acompanhada por uma formação docente atenta às inovações científico-tecnológicas, suas relações dialógicas com a sociedade e seus modos de vida, às influências de determinantes econômicos e políticos.

No texto que se segue pretendemos apresentar as percepções de um grupo de licenciandos em Ciências da Natureza - Biologia, Física e Química -, apuradas no contexto da participação em um curso de extensão sobre as relações estabelecidas entre ciência, tecnologia e sociedade acerca de como devem ser encaminhadas as controvérsias científicas. Para tanto, iniciaremos estabelecendo um marco teórico para tratar de ambas questões envolvidas em nosso objetivo: controvérsias científicas e modelos decisórios em ciência e tecnologia. Ao longo do caminho, como é natural, se agregarão reflexões sobre o papel da educação científica e do ensino de ciências e, principalmente, da formação docente no enfrentamento destas questões, atuais, necessárias e relevantes para a sociedade.

\section{A natureza da ciência e da tecnologia e as controvérsias científicas}

O dicionário Houaiss define "controvérsia" como proposta ou questão sobre a qual muitos divergem. Complementa a definição a etimologia da palavra, que é formada pelo prefixo "contra" - indicando enfrentamento - e "ver", de verter, virar. A definição lexicográfica declara a natureza social do fenômeno da controvérsia, indicando a impossibilidade de sua redução a categorias lógicas, psicológicas ou epistêmicas.

Por este entendimento, adotaremos no presente texto a expressão "controvérsias científicas" para nos referirmos às controvérsias sociocientíficas. Todas as controvérsias têm caráter social, o que difere é o alcance deste debate: algumas controvérsias são mais restritas a espaços acadêmicos, enquanto outras resvalam em temas sociais de interesse público e ocupam o cenário de disputa política em torno de ações governamentais. O próprio fato de extravasar o campo lógico-cognitivo acarreta a complexificação de seu estudo, que exige contribuições de campos distintos, como a sociologia, filosofia, história e outras ciências humanas e sociais (GIERE, 2003).

No campo das ciências da natureza, a persistência do paradigma positivista - tributário da visão moderna de ciência - presume alguma resistência à ideia de que controvérsias científicas tenham uma dimensão social.

Esta concepção de ciência, a qual chamaremos de concepção herdada de ciência, concebe o desenvolvimento científico como um processo que segue uma racionalidade rígida, autônoma, sem interferência de fatores não-epistêmicos, quais sejam: sociais, políticos, psicológicos, entre outros. Tal código, ou modo de operação, segundo García e colaboradores (2003), garantiria que, frente à dois desenvolvimentos teóricos equipolentes e baseados em evidências empíricas, um critério metacientífico igualmente objetivo poderia dirimir a disputa. Tal critério seria fundado em virtudes cognitivas quase sempre invocadas: "as da simplicidade, do poder preditivo, da fertilidade teórica e do poder explicativo" (GARCÍA et al., 2003, p.15).

Com o positivismo, a ciência se reafirma enquanto instância independente e autônoma e é reforçada enquanto forma superior de conhecimento. O paradigma positivista, nas palavras de Engelhardt e Caplan (2003, p. 8):

[...] é o de um grande silogismo fundamentado pela comunidade científica, visto como o equivalente epistêmico do observador imparcial, racional e plenamente informado, posicionado na teoria ética. Nos termos de tal visão, e dada a crença no conhecimento da realidade, busca-se uma resposta final e verdadeira, que deve, em princípio, estar 
disponível para encerrar a controvérsia (ENGELHARDT, CAPLAN, 2003, p. 8, tradução nossa).

Em seus desdobramentos mais sofisticados, destaca-se o Positivismo Lógico, que se desenvolve na alvorada do século XX no contexto dos encontros do Círculo de Viena, cujo principal expoente foi Rudolf Carnap (1891-1970). O Círculo tinha como principal tese o critério empirista do significado, segundo o qual o sentido de uma frase empírica é seu método de verificação. Outra decorrência desse pensamento é a circunscrição do pensamento lógico a um processo não criativo de transformações tautológicas.

No século XX as meta-ciências começam a questionar o cientificismo e a ideia de desenvolvimento temporal deste corpo de conhecimento como linear e cumulativo. Esse paradigma começa a se enfraquecer de forma contundente a partir da década de 1960. Nessa mesma década é lançado o livro A Estrutura das Revoluções Científicas, de Thomas Kuhn, que propõe uma perspectiva histórica das teorias científicas. Nesta linha, teorias científicas não são um conjunto de enunciados e axiomas, mas sim uma estrutura de conceitos que evoluem historicamente, tanto inter-teoricamente quanto intra-teoricamente, ou seja, a validade dos enunciados científicos não possui características que os tornem mais racionalmente justificáveis que outros enunciados em outros contextos - cada comunidade determina os padrões para acatar evidências. É dizer:

\begin{abstract}
As regras para obter evidências e tirar conclusões, [contrariamente ao paradigma positivista], mudam na ciência ao longo do tempo. É preciso, como consequência, qualificar controvérsias científicas com um índice sócio-histórico para identificar uma controvérsia científica com uma comunidade científica específica, suas regras para selecionar evidências relevantes para um debate e suas regras para raciocinar com base nessas evidências. Ou seja, uma controvérsia científica é identificada com uma comunidade científica específica, entendida como um grupo de partes interessadas em um debate científico que, em um ponto específico da história, compartilha regras comuns de evidência e inferência (ENGELHARDT, CAPLAN, 2003, p. 8, tradução nossa).
\end{abstract}

Outra referência importante que antagoniza com perspectivas positivistas é o Programa Forte da Sociologia da Ciência que confronta a ciência não apenas quanto ao seu funcionamento ou caráter institucional, mas o próprio teor do conhecimento científico também é objeto de análise.

Os princípios programáticos do Programa Forte (BLOOR, 1991, p.7) são: (a) causalidade: as crenças dos cientistas são causadas socialmente e não racionalmente; (b) imparcialidade: as causas sociais devem explicar tanto o sucesso quanto o fracasso de teorias científicas; (c) simetria: as mesmas causas devem explicar tanto teorias racionais quanto irracionais; e (d) reflexividade: a sociologia da ciência também deve obedecer aos preceitos do programa. Bloor, ao enunciar os princípios do Programa Forte da Sociologia do Conhecimento, subverte a concepção há muito sustentada na epistemologia - pelo menos desde Aristóteles de que verdade, racionalidade e validade fossem nossos fins naturais, tendências humanas.

O princípio da simetria, especialmente, foi formulado com intuito de não recorrer a fatores racionais para explicar o sucesso de algumas teorias e a fatores sociais/psicológicos para explicar o fracasso de outras (DUARTE, 2007), dito de outra forma, todas as explicações do desenvolvimento científico devem ser simétricas, ou seja, os vencidos e vencedores da história da ciência. Nas palavras de Latour e Woolgar (1997, p. 23), “ou as explicações sociais e 
psicológicas, econômicas são usadas apenas para explicar por que um cientista enganou-se, e então elas não têm valor, ou devem ser empregadas simetricamente, de modo a explicar porque esse cientista errou e porque aquele outro acertou".

As premissas da forma habitual de tratar o conhecimento, cujas raízes filosóficas foram hegemônicas durante ao menos 21 séculos, são desafiadas por uma sociologia do conhecimento que incorpora fatores sociais como constitutivos da própria ideia de conhecimento científico (SHAPIN, 1995), é uma epistemologia social. Ao contrário do que possa parecer, esta forma de relativismo não abandona a noção de verdade, mas a ancora a um sentido social: a aceitação de uma teoria faz com que ela seja a base para seu entendimento e adaptação do mundo (BLOOR, 1991). Daí o Programa Forte ser identificado como um construtivismo social da ciência, ou seja: quando as pessoas confrontam a experiência de seus sentidos, elas o fazem dentro de uma estrutura de conhecimento preestabelecida, vigente em sua comunidade e dentro de uma estrutura de propósitos sustentada e partilhada por esta mesma comunidade (SHAPIN, 1995). Segundo Collins (1983):

\begin{abstract}
A sociologia do conhecimento científico [...] preocupa-se precisamente com o que passa a ser considerado conhecimento científico e como ele passa a ser considerado como tal. A frase crucial aqui é "passa a ser considerado", já que nenhum conhecimento além da atividade científica humana é reivindicado. A variante mais forte dessa visão é frequentemente chamada de "relativismo" já que não assume pontos fixos no mundo físico nem um domínio fixo da lógica que fosse compelir acordos entre observadores imparciais ou pensadores de culturas radicalmente diferentes. Nem a Natureza nem a Racionalidade são tomadas como universais auto-evidentes da cultura humana. A investigação que seja baseada neste programa diz respeito a como certas visões sobre o mundo físico e matemático passa a ser considerado como correto dentro de uma sociedade, e não como a sociedade pode ser organizada para que a verdade surja. Escritores do gênero relativista costumam falar de a "construção social" do conhecimento científico (COLLINS, 1983, p.267, tradução nossa).
\end{abstract}

Tributário do Programa Forte, o Programa Empírico do Relativismo - EPOR no acrônimo inglês, foi desenvolvido nas décadas de 1970 e 1980 por Harry Collins e Trevor Pinch. A ênfase de seus trabalhos reside na construção sociológica empírica de controvérsias científicas, sobretudo nas ciências duras.

Collins (2011) busca reestruturar o pensamento e o discurso sobre a ciência, considerando a fragilidade epistemológica e política da concepção essencialista, herdada da forma tradicional de pensar o conhecimento científico. Tomando por base, sobretudo os princípios de simetria e reflexividade, o EPOR busca deslocar sua análise da ciência enquanto fornecedora de verdades para uma análise do significado da expertise sobre a qual reside a prática da ciência e da tecnologia (COLLINS; EVANS, 2009).

O EPOR enquanto programa de pesquisa parte das etapas: (a) mostrar a flexibilidade interpretativa dos resultados experimentais - ou seja, os achados científicos são abertos a mais de uma interpretação, de forma que o foco da explicação sobre o desenvolvimento científico não é mais o mundo natural, senão o mundo social; (b) revelar mecanismos sociais, retóricos, institucionais entre outros que favorecem a promoção do consenso sobre a "verdade científica" frente a controvérsias - a interpretação é negociada entre os cientistas mais influentes, dotados de autoridade para opinar sobre determinada controvérsia; e (c) relacionar estas formas de fechamento de controvérsias científicas com meios socioculturais e políticos mais amplos (COLLINS, 1981). 
A presente recuperação de teorias aqui realizada não se pretende exaustiva. Outras abordagens recentes discutem as fronteiras entre ciência e política (COZZENS et. al, 2001; BRAUN, 2003; ELZINGA et al, 2001; JASANOFF, 1897, 2003, 2004, 2017). Tais abordagens, caracterizadas por uma aproximação interdisciplinar constante, apontam para debates contemporâneos em Política Científica e Tecnológica.

Considerando as perspectivas teóricas apresentadas, controvérsias científicas precisam encontrar fechamento, uma vez que eventualmente terão impacto no mundo real através de políticas públicas, que cada vez mais se valem dos resultados da ciência para justificar e embasar decisões. Essas perspectivas apresentadas, em que pese a radicalidade de suas implicações, deverão sustentar o estudo que empreenderemos adiante sobre as percepções de licenciandos acerca de modelos decisórios em controvérsias científicas.

\section{Participação Social em Ciência e Tecnologia e Modelos Decisórios}

Há dificuldades importantes no que diz respeito à divulgação de temas de $\mathrm{C} \& \mathrm{~T}$, muitas delas derivadas de uma tendência em polarizar debates científicos de forma artificial, os simplificando em uma apresentação muitas vezes dual de temas complexos (GOODELL, 2003). Como resultado, o significado das evidências científicas se perde em meio à ambiguidade introduzida pelos elementos políticos ou sociais da disputa.

Em consideração à necessária democratização do debate científico e da própria ciência em uma sociedade crescentemente cercada de artefatos tecnológicos, é indispensável a promoção do letramento científico-tecnológico, como meio de garantir a participação social em temas de Ciência e Tecnologia. Em outras palavras:

\footnotetext{
[...] o desenvolvimento científico-tecnológico é um processo social conformado por fatores culturais, políticos e econômicos, além de epistêmicos; a mudança científicotecnológica é um fator determinante principal que contribui para modelar nossas formas de vida e de ordenamento institucional; constitui um assunto público de primeira magnitude; compartilhamos um compromisso democrático básico; portanto, deveríamos promover a avaliação e controle social do desenvolvimento científicotecnológico, o que significa construir as bases educativas para uma participação social formada, assim como criar os mecanismos institucionais para tornar possível tal participação. (GARCÍA et al. 2003, p. 127)
}

Nessa esteira, controvérsias científicas vêm sendo empregadas e discutidas largamente na pesquisa em ensino de ciências em alusão à premência de uma reorientação epistemológica como etapa necessária à renovação do ensino de ciências (CACHAPUZ et al, 2005) para atender aos desafios impostos pela perspectiva da participação cidadã na tomada de decisão em assuntos de ciência.

Muitas pesquisas em educação científica discutem os resultados de experimentos didáticos relativos ao emprego de controvérsias científicas (BULLA, MEGLHIORATTI, 2016; RAICIK, PEDUZZI, ANGOTTI, 2018; HOFFMAN, DUSO, 2012; REIS, GALVÃO, 2005; GALVÃO, REIS, FREIRE, 2011), com intuito expresso de promover o avanço na sua incorporação enquanto metodologia de ensino. Sobre o tema, afirmam Santos e Mortimer (2001, p. 107): 
A adoção de temas envolvendo questões sociais relativas à C\&T, que estejam diretamente vinculadas aos alunos, nos parece ser de primordial importância para auxiliar na formação de atitudes e valores. Para isso, parece ser essencial o desenvolvimento de atividades de ensino em que os alunos possam discutir diferentes pontos de vista sobre problemas reais, na busca da construção coletiva de possíveis alternativas de solução. A informação científica sobre o tema envolvido é imprescindível, todavia ela não é suficiente se desejamos ir além da mera alfabetização de fatos científicos. [...]. Isso exige uma mudança de postura dos professores de ciências, no sentido de incorporar às suas aulas, discussões sobre temas sociais, envolvendo os aspectos ambientais, culturais, econômicos, políticos e éticos relativos à C\&T; atividades de engajamento social dos alunos, por meio de ações concretas; e a discussão dos valores envolvidos (SANTOS, MORTIMER, 2001, p. 107).

Como dizem Santos e Mortimer (2001), a informação é condição necessária, porém não suficiente para garantir o letramento em C\&T. Ainda para o autor, retomando Santos e Schnetzler (2014), esta perspectiva envolve "a compreensão do impacto da ciência e da tecnologia sobre a sociedade em uma dimensão voltada para a compreensão pública da ciência dentro do propósito da educação básica de formação para a cidadania” (SANTOS, 2007, p. 479).

Com a popularização da ciência via educação formal - institucionalizada, sistemática, planejada intencionalmente - e não formal - atividades de baixo grau de estruturação e sistematização, que implica em relações pedagógicas não-formalizadas - nos aproximamos da possibilidade de democratização da participação em assuntos de C\&T.

Neste sentido, Habermas (1980) encara a especialização excessiva das ciências como uma fragilidade, ao que propõe a categorização de modelos decisórios para C\&T e a sociedade: (a) o tecnocrático: no qual o caráter social e histórico do conhecimento científico é desconsiderado e a autoridade do especialista impõe primazia na definição de diretrizes; (b) o decisionista: para o qual a voz do especialista comparece de forma a intermediar o processo decisório, ou seja, ele auxilia na consecução de objetivos nomeados socialmente; e (c) o pragmático: o mais democrático de todos, fundado no diálogo e negociação permanentes entre os atores envolvidos, o que torna as decisões fundamentalmente políticas.

A partir da adesão a um ou outro dos modelos propostos por Habermas (1980), é possível rastrear reversamente as crenças sobre a natureza da ciência, e por sua vez, as crenças sobre controvérsias científicas. Considerando a tarefa específica da educação formal enquanto viabilizadora da popularização e democratização do acesso a temas de ciência, é premente dotar professores de ciências de subsídios teóricos e práticos voltados para estimular condutas reflexivas e transformadoras que viabilizem a construção de estratégias de ensinoaprendizagem cuja tônica seja o desejo de investigar e agir sobre seus contextos de atuação e da compreensão da complexa relação ciência-tecnologia-sociedade (NASCIMENTO; FERNANDES; MENDONÇA, 2012).

Considerando todos aspectos levantados, reiteramos o objetivo desta pesquisa: apresentar as percepções sobre modelos decisórios em C\&T emergentes no discurso dos licenciandos de cursos de Biologia, Química e Física que participaram de um curso sobre as inter-relações ciência, tecnologia e sociedade.

\section{0 contexto da pesquisa: aspectos metodológicos da coleta e análise de dados}


A presente pesquisa foi desenvolvida no contexto de um curso de extensão à distância, oferecido no segundo semestre de 2018 a 36 participantes. O público alvo foi licenciandos em ciências - Biologia, Física ou Química. O objetivo geral do curso foi debater aspectos das relações entre ciência, tecnologia e sociedade e o impacto desta abordagem educacional no ensino de ciências. O curso estruturou suas atividades em torno de três eixos temáticos: a racionalidade científica, o desenvolvimento tecnológico, relações ciência-tecnologiasociedade. Tais eixos foram dispostos de modo a apresentar conhecimentos conceituais interdisciplinares e as discussões associadas, articuladas a partir de controvérsias científicas selecionadas. A articulação dos eixos propostos com as controvérsias científicas e estratégias pedagógicas empregadas são estruturadas conforme Quadro 1:

Quadro 1 - Eixos, Aspectos Sociocientíficos Abordados e Estratégias Pedagógicas empregadas.

\begin{tabular}{|c|c|c|}
\hline Eixos & Aspectos Abordados & Estratégias Pedagógicas \\
\hline $\begin{array}{l}\text { Racionalidade } \\
\text { Científica (RC) }\end{array}$ & $\begin{array}{l}\text { O uso de Agrotóxicos na } \\
\text { agricultura: o dissenso } \\
\text { científico }\end{array}$ & \multirow{3}{*}{$\begin{array}{l}\text { Fórum de Discussão: atividade de debate } \\
\text { que projeta questionamentos sobre as } \\
\text { representações particulares do que os } \\
\text { estudantes pensam ser a melhor forma de } \\
\text { viver em nível pessoal, social e mundial, } \\
\text { visando explorar a origem de suas } \\
\text { convicções e a tomada de decisão com base } \\
\text { em argumentos. }\end{array}$} \\
\hline $\begin{array}{l}\text { Desenvolvimento } \\
\text { Tecnológico (DT) }\end{array}$ & 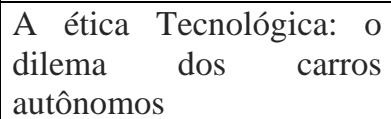 & \\
\hline $\begin{array}{c}\text { Ciência- } \\
\text { Tecnologia- } \\
\text { Sociedade (CTS) }\end{array}$ & $\begin{array}{l}\text { Sustentabilidade e os } \\
\text { impactos da Ciência e } \\
\text { Tecnologia }\end{array}$ & \\
\hline
\end{tabular}

Fonte: Elaboração Própria.

Cada eixo do curso se estruturou em torno de um aspecto sociocientífico. Tais aspectos foram apresentados em forma de controvérsia em dois eixos: Racionalidade Científica abordando a controvérsia científica dos agrotóxicos, e Desenvolvimento Tecnológico organizado pela controvérsia dos carros autônomos.

Tema de pronunciado interesse público, a questão dos agrotóxicos é atual considerando a discussão ocorrida durante os anos de 2018 e 2019 no Congresso Nacional brasileiro acerca do Projeto de Lei 6.299/2002, sobre regulação e controle do uso de agrotóxicos no Brasil. A controvérsia em torno dessa questão é exposta no Dossiê da Associação Brasileira de Saúde Coletiva - Abrasco:

Uma série de questões que nós não compreendemos corretamente nos obriga a fazer novos questionamentos relacionados com os agrotóxicos, e a mostrar como são frágeis as bases científicas que dão sustentação ao seu uso para fins agrícolas ou de saúde pública: a) Como se dão as reações com todas as proteínas que interagem no organismo, como um sistema integrado?; b) Como a inibição da enzima acetilcolinesterase pode prever outros efeitos não avaliados nos expostos?; c) Está perfeitamente adequada a dosimetria utilizada aos fenômenos do metabolismo e da toxicocinética?; d) As diferenças de suscetibilidade (idade e genética) estão consideradas na avaliação dos efeitos dos agrotóxicos?; e) Estão incluídas todas as fontes de exposição (consumo de alimentos, de água, por exemplo) no balanço da exposição?; f) A exposição múltipla e todos os agentes que atuam simultaneamente, potencializando a toxicidade, são considerados? (ABRASCO, 2012, p. 48) 
Já em função da quase inextricável relação entre ciência e tecnologia, se torna essencial que se discuta a questão da ética tecnológica. Escolhemos o dilema dos carros autônomos como pretexto para tal incursão. Aqui a escolha se deveu à dimensão axiológica de questões CTS, tendo em vista que, conforme Auler (2002), esta dimensão compõe uma orientação CTS para o ensino de ciência. Essa controvérsia, por sua vez pode ser formulada à medida em que se compreende que automóveis autônomos - controlados pela inteligência artificial - funcionam segundo um algoritmo pré-programado para decidir o que fazer em uma situação de acidente iminente. As alternativas mais extremas se colocam em termos de adotar um paradigma utilitarista - minimizar o número de envolvidos no acidente - ou proteger o passageiro assumindo o princípio de que tais carros devam ser seguros para seus usuários. Outros questionamentos seguem, como por exemplo: quem deve decidir sobre tais algoritmos: as empresas que produzem os carros, o poder público, o usuário final?

Do ponto de vista metodológico, o substrato empírico obtido das interações registradas no curso foi analisado a partir do referencial da Análise Textual Discursiva - ATD, de orientação hermenêutico-fenomenológica, que se situa entre a Análise de Discurso e Análise de Conteúdo. A ATD é:

\footnotetext{
um processo auto-organizado de construção de compreensão em que novos entendimentos emergem a partir de uma sequência recursiva de três componentes: a desconstrução dos textos do corpus, a unitarização; o estabelecimento de relações entre os elementos unitários, a categorização; o captar o emergente em que a nova compreensão é comunicada e validada (MORAES; GALIAZZI, 2011, p. 12).
}

Os aspectos procedimentais da ATD orientam a desmontagem dos textos, seguido pelo estabelecimento de relações a fim de captar novas compreensões emergentes. A unitarização representa o desmembramento do texto para transformá-lo em unidades elementares, recortes e fragmentos de textos reunidos a partir de diferentes focos linguísticos. Nesse processo se revelam as unidades de análise. Essa etapa envolve um processo desconstrutivo e recursivo, de mergulho nos sentidos atribuídos ao corpus - representado pelos dados coletados, originando as unidades de significado.

Em seguida, ocorre a organização de unidades em categorias iniciais elaboradas por aproximação, das quais se sintetizam categorias intermediárias, que, no movimento de imersão do pesquisador, resultam nas categorias finais construídas no processo de compreensão do fenômeno. A categorização, portanto, apresenta-se "como processo de aprendizagem e comunicação de novos entendimentos em um movimento de síntese e construção de sistemas de categorias com as novas aprendizagens e compreensões que originam um metatexto" (SOUSA; GALIAZZI, 2018, p. 800). Categorizar é reunir por semelhança. Tal processo pode ocorrer de forma apriorística ou não e ainda de forma mista, revelando pressupostos epistemológicos e paradigmáticos. Em nossa pesquisa, pelo corpus ter sido produzido segundo a orientação de atividades preestabelecidas em um curso de extensão, consideramos que o processo foi misto.

O produto final da aplicação da ATD é um metatexto - apresentado como resultado da pesquisa - que traz à tona as ideias emergentes das análises e os argumentos elaborados pelo pesquisador no processo investigativo, de forma a comunicar compreensões atingidas (MORAES; GALIAZZI, 2011). O resultado desta metodologia representa as interpretações pessoais do pesquisador, abalizando fidedignamente as informações obtidas através dos sujeitos 
das pesquisas, as conferindo validade através da ancoragem empírica das conclusões alcançadas. O Quadro 2 representa as etapas compreendidas pela ATD:

Quadro 2 - Fluxo metodológico da Análise Textual Discursiva.

\begin{tabular}{|c|c|c|}
\hline 1. Unitarização & 2. Categorização & 3. Metatexto \\
\hline Análise & Síntese & Descrição/Interpretação \\
\hline Desconstrução, Leitura & Relações, Comparações, & $\begin{array}{c}\text { Movimento produtivo de } \\
\text { teorização }\end{array}$ \\
Cuidadosa, Seleção do corpus & Agrupamento & Novas Compreensões \\
\hline Unidades de Significado & Categorias de Análise & Fonte: Elaboração Própria.
\end{tabular}

Os processos metodológicos foram orientados em proveito da compreensão em profundidade do ideário dos professores em formação acerca dos modelos decisórios a serem empregados no fechamento de controvérsias científicas. O corpus de análise foi extraído das atividades e interações via Plataforma Moodle e é relativo aos Fóruns de Discussão - momento de maior interação dialógica no curso ${ }^{1}$. A categorização buscou estabelecer relações e comparações, agrupando por semelhança as unidades de significado obtidas na etapa anterior. O metatexto é apresentado na seção seguinte, onde a teorização da autora é intercalada com a apresentação de unidades de significado que formaram as categorias de análise. Os excertos relativos às unidades são apresentados por meio de quadros e identificado por códigos utilizados para organizar o corpus de análise.

\section{Percepções de licenciandos em Ciências da Natureza}

Percepções acerca de modelos decisórios se apoiam na leitura do que são e o que representam controvérsias científicas. Tal leitura, por sua vez, se fundamenta na forma como se interpreta a própria racionalidade científica. Desta forma, iniciaremos a análise de nossos resultados indicando as categorias: (a) racionalidade científica; e (b) modelos decisórios.

O discurso manifesto, sobretudo no contexto do eixo Racionalidade Científica - RC, revelou a complexidade de oferecer uma definição lexical para a ciência, reiteradamente ignorada e relegada a um plano pragmático e ateórico, como o corpo discursivo afirma em:

Quadro 3 - Excerto de corpus de análise

[RC-2] $\begin{aligned} & \text { definir ciência é uma tarefa muito difícil, na prática sabemos identificá-la, porém, } \\ & \text { defini-la já é uma tarefa mais complexa. }\end{aligned}$ Fonte: Atividades e interações via Plataforma Moodle no contexto do curso.

\footnotetext{
${ }^{1}$ Em atendimento às garantias éticas e legais, a presente pesquisa passou pelo Comitê de Ética em Pesquisa do Instituto Federal de Educação, Ciência e Tecnologia de Goiás e atendeu aos critérios estabelecidos pela Resolução do Conselho Nacional de Saúde $n^{\circ}$ 466, de 12 de dezembro de 2012. Os participantes assinaram termo de consentimento livre e esclarecido, garantindo sigilo e confidencialidade da identidade dos envolvidos, liberdade para decidir a qualquer tempo pela saída da pesquisa e informando detalhadamente as condições da pesquisa. Nele, o/a participante optou por permitir ou não o uso das atividades pedagógicas produzidas no âmbito do curso em sua integralidade ou em parte, sendo garantido seu anonimato.
} 
Quer dizer, as práticas científicas e a atividade científica fazem parte do cotidiano dos cursistas, muito embora esteja ausente de forma clara a abstração sobre o que é que fazem quando fazem ciência. Esta falta de reflexão crítica é objeto de atenção de Schatzmann (1994 apud AULER, 2002, p.81) quando afirma:

\begin{abstract}
A existência de uma crise de consciência entre os cientistas resulta de conflito entre o conteúdo da ciência e a situação social da ciência. A pesquisa fundamental, em sua motivação, ignora os interesses da produção e as necessidades do poder político. Sua única meta a descoberta das leis da natureza. [...]. Esta alienação é sentida violentamente pelos jovens pesquisadores, no campo das ciências da natureza, onde, entretanto, a noção de realidade objetiva não pode ser questionada (SCHATZMANN, 1994, apud AULER, 2002, p.81, grifo nosso).
\end{abstract}

Também essa é a crítica de Horkheimer (2002), filósofo da Escola de Frankfurt. Para ele, a ciência é capaz de fundamentar seus passos, mas não o é quanto a compreender a si própria e à orientação de seu trabalho. Essa constatação sobre a concepção subjacente de ciência culminou em construções discursivas oscilantes, que em um primeiro momento compreenderam a atividade científica como dotada de um algoritmo rígido que legitima a ciência enquanto possuidora de racionalidade autônoma e alheia a condicionantes sociais, políticos ou psicológicos:

Quadro 4 - Excerto de corpus de análise

\begin{tabular}{|c|l|}
\hline [RC-3] & $\begin{array}{l}\text { Bom, ciência advém da construção de uma dúvida, seguido de uma solução, que é } \\
\text { a pesquisa, onde [sic] pode ser realizada pelo método dedutivo, por exemplo. }\end{array}$ \\
\hline
\end{tabular}
Fonte: Atividades e interações via Plataforma Moodle no contexto do curso.

O discurso manifesto em [RC-3] remete à concepção herdada da ciência, para a qual o método empirista-indutivista leva de forma segura da observação às teorias, produzindo um conhecimento fundado em evidências observacionais, em outras palavras: a observação antecede a teoria. Trata-se de um espectro de visões sobre a ciência de ascendência baconiana e representadas no século XX pelo positivismo lógico.

A orientação discursiva, a despeito de encontrar dificuldades para definir ciência, ainda parece apelar para a concepção herdada de ciência e encontra eco no encaminhamento sugerido para dirimir controvérsias científicas, expresso reiteradamente pelo entendimento de que:

Quadro 5 - Excerto de corpus de análise

\begin{tabular}{|c|l|}
\hline [RC-12] & $\begin{array}{l}\text { [controvérsias científicas] podem ser resolvidas com resultados de pesquisas } \\
\text { concretas e de metodologias que sejam informadas. }\end{array}$ \\
\hline [RC-23] & $\begin{array}{l}\text { As controvérsias científicas devem ser resolvidas a partir de dados sólidos e } \\
\text { precisos, o que dá muito trabalho, mas é o único meio para cessar com esse } \\
\text { conflito. }\end{array}$ \\
\hline
\end{tabular}

Fonte: Atividades e interações via Plataforma Moodle no contexto do curso.

Controvérsias científicas, corroborando o modelo de racionalidade tecnocientífica expresso anteriormente, se dão, segundo nos permite inferir o discurso manifesto, a partir do mau funcionamento do algoritmo que rege a atividade científica, e deve ser fruto de conciliação com base em mais pesquisas e difusão científica. Poderia afirmar-se que esta percepção 
emergente no discurso contraria a noção de que as controvérsias científicas são a materialização da incomensurabilidade de paradigmas, conforme Kuhn (AULER, 2002). Entretanto, a noção de incomensurabilidade se dá numa dimensão interteórica, enquanto algumas controvérsias extravasam a perspectiva epistemológica, já que possuem aspecto social relativo a apropriação e decisões políticas, cujo impacto fora dos laboratórios transborda o aspecto cognitivo ou ontológico. O mesmo discurso sobre a atividade científica, quando confrontado com a historicidade da ciência, afirma de forma conscienciosa que:

Quadro 6-Excerto de corpus de análise

\begin{tabular}{|c|l|l|}
\hline [RC-8] & $\begin{array}{l}\text { entendi [...] que a Ciência é um estudo que tem um começo } \\
\text { (questionamento/hipóteses), meio (teste da hipótese e assimilações) e fim } \\
\text { (conclusão/ comprovação da hipótese), que é o que constitui parte do método } \\
\text { científico. Entretanto, vejo a Ciência como um método similar, onde tem um "fim } \\
\text { parcial", pois chegamos a uma conclusão prévia sobre algo, uma conclusão que } \\
\text { atenda à nossa sede de conhecimento naquele momento, mas não para sempre, } \\
\text { pois, se fosse para sempre, não haveria porque continuar pesquisando. }\end{array}$ \\
\hline
\end{tabular}

Fonte: Atividades e interações via Plataforma Moodle no contexto do curso.

O discurso manifesto revela em [RC-8], acerca do desenvolvimento das ciências, um entendimento segundo o qual há descontinuidades e rupturas, o que o aproxima de uma concepção racionalista afeita a um processo dialético que busca conciliar os aspectos racionalistas e empiristas com relação à construção do conhecimento científico. Tais rupturas, as quais faz menção indireta o fragmento [RC-8], surgem discursivamente como motrizes da ciência. Esta perspectiva é propalada sobretudo por Gaston Bachelard e influencia trabalhos posteriores de Thomas Kuhn. O método científico, portanto, deflagra um processo de construção mais complexo que envolve fatores sociais e históricos além dos epistêmicos:

Quadro 7 - Excerto de corpus de análise

\begin{tabular}{|c|l|}
\hline [RC-28] & a ciência não é construída individualmente, mas sim em coletivo e cooperação. \\
\hline$[$ RC-9] & $\begin{array}{l}\text { o conhecimento científico carrega consigo uma carga de conhecimentos culturais, } \\
\text { sociais e pessoais. }\end{array}$ \\
\hline
\end{tabular}

Essa visão social da construção da ciência encontra fundamentos nos trabalhos de ascendência europeia, sobretudo o Programa Forte da Sociologia do Conhecimento, o Programa Empírico de Sociologia do Conhecimento, e o seu sucessor, a Construção Social da Tecnologia:

\footnotetext{
A construção social da ciência compõe, portanto, a noção de que os resultados da ciência (por exemplo, uma classificação taxonômica) ou os produtos da tecnologia (por exemplo, a eficiência de um artefato) foram socialmente construídos; quer dizer, que tais resultados ou produtos são o ponto de chegada de processos contingentes (não inevitáveis) nos quais a interação social tem um peso decisivo. Há diversos tipos de construtivismo social, conforme se fale, por exemplo, de um ou outro tipo de objeto construído (fatos, propriedades, categorias...) e se aceite ou não a concorrência de fatores epistêmicos (GARCÍA et al., 2003, p.158).
} 
A aparentemente contraditória conciliação entre a construção social da ciência e a importância do método científico demonstra o entendimento de que admitir a construção social da ciência não implica que ela deixe de ser um corpo de conhecimento com princípios, leis e teorias, que buscam explicar o mundo que nos rodeia. A construção social da ciência, nessa perspectiva, se dá em benefício da representação de sua dinâmica, resultando numa interpretação mais plausível de seus resultados e processos.

Ainda na tentativa de reconstruir a integralidade do discurso sobre a concepção da atividade científica, emergem leituras sofisticadas a respeito da epistemologia do conhecimento científico no que diz respeito aos pressupostos da ciência quando afirma que:

Quadro 8 - Excerto de corpus de análise

\begin{tabular}{|l|l|}
\hline [RC-10] & $\begin{array}{l}\text { Antes mesmo da observação há a teoria, uma vez que não é possível observar tudo } \\
\text { de maneira imparcial. Nossa mente "recorta" nosso olhar para aquilo que, } \\
\text { previamente, nos interessa, sejam por construções sociais, pessoais ou culturais, } \\
\text { antes mencionadas. [...] a atitude de burlar as regras do método científico é quase } \\
\text { que uma "necessidade" para seu progresso. }\end{array}$ \\
\hline
\end{tabular}

Fonte: Atividades e interações via Plataforma Moodle no contexto do curso

O discurso manifesta o entendimento de que uma teoria leva à outra, salientando "a carga teórica da observação", ou seja: percebe que as teorias científicas frequentemente funcionam de forma cumulativa, de forma que uma teoria fora da cadeia, que introduza novos conceitos e elementos tende a ser rejeitada. Compreende ainda uma dimensão da subversão do método, no que ressoa a contribuição de Paul Feyerabend, para quem a ciência se beneficiaria de um anarquismo metodológico, uma vez que o caráter prescritivo do método impõe limites às atividades dos cientistas, restringindo assim, o progresso científico.

As manifestações discursivas também são sensíveis ao fato de que ao observar, já privilegiamos alguns aspectos entre as inúmeras informações empiricamente recebidas, uma vez que o olhar humano é intencional, é dirigido por uma intenção, tendendo a privilegiar determinados aspectos em detrimento de outros:

Se a observação é imprescindível à ciência, ao observarmos um fenômeno não o fazemos sem usar um plano de fundo teórico: o que se vê depende tanto das impressões sensíveis - objetivas, quanto do conhecimento prévio, das expectativas, dos pré-juízos e do estado interno geral do observador! Em outras palavras, os fatos nunca constituem o dado primeiro, mas sim, resultam de nossa observação interpretativa: a observação está sempre impregnada de teoria (KNELLER, 1980, p. 80).

Kneller (1980) reflete os preceitos do EPOR, sobretudo a flexibilidade interpretativa. Quanto à interpretação da percepção de nossos cursistas, tal movimento nos permite inferir que o discurso em voga oferece uma concepção híbrida da atividade científica, que recusa uma forma vulgar de construtivismo, a exemplo de um que permita questionar a realidade objetiva, e se ancora em características procedimentais e metodológicas das ciências - de modo a preservar seus conteúdos cognitivos, fruto de critérios epistêmicos, muito embora ainda reconheça fatores sociohistóricos intervenientes em seu funcionamento e esteja atenta à carga teórica da observação. 
Estes aspectos podem ser comparados com o quadro teórico oferecido por Giere (2003) como um ponto de partida para pensar controvérsias científicas. Para ele, o valor de enunciados científicos deve considerar que: (a) o valor lógico que pode lhes ser atribuído é binário verdadeiro ou falso - no sentido de que correspondem ou não a algum aspecto da realidade; (b) métodos da ciência são fiáveis - embora não infalíveis - para auferir verdade ou falsidade para uma grande maioria de enunciados científicos e sua justificação se dá pelos próprios procedimentos científicos dos quais são produtos; (c) a fiabilidade com a qual tais enunciados são produzidos pode, com frequência, ser determinada de forma segura.

Quanto à análise dos modelos decisórios emergentes para fechamento de controvérsias, nossa segunda categoria de análise, a preocupação principal que surge são os caminhos para a efetivação da participação social, orientados por uma vaga necessidade de promoção de um processo decisório democrático cujo postulado fosse uma escolha esclarecida do público, conscientizado através da educação científica:

Quadro 9 - Excerto de corpus de análise

\begin{tabular}{|l|l|}
\hline [RC-13] & $\begin{array}{l}\text { é importante discutir esta temática [agrotóxicos] na sociedade, pois é um tema que } \\
\text { envolve a todos os seres vivos. Através da promoção de palestras, eventos, } \\
\text { mobilizações, feitas pelos órgãos competentes relacionados à liberação desses } \\
\text { produtos [agrotóxicos]; }\end{array}$ \\
\hline
\end{tabular}

Fonte: Atividades e interações via Plataforma Moodle no contexto do curso

O pacto democrático só se realiza quando a participação social é efetiva e qualificada, e transcende os limites do mero sufrágio. Tal situação requer um fortalecimento de outras instâncias representativas - o tecido institucional de atores sociais, seja a sociedade civil organizada, sindicatos, associações ou até mesmo conselhos gestores em órgãos públicos. Coloca-se, portanto, a necessidade de participação social:

\begin{abstract}
[...] por vários motivos: a) muitos dos graves problemas sociais contemporâneos não são solúveis utilizando apenas critérios científico-tecnológicos, considerando que estes estão configurados dentro de determinadas relações sociais; b) o direito que a sociedade, como um todo, possui de participar em definições que envolvem seu destino; c) o atual direcionamento, a definição da agenda de investigação, dá-se, cada vez mais, de tal forma que sejam ativados, seletivamente, aqueles campos de investigação, a exemplo da biotecnologia, encaixáveis na lógica da maximização do lucro privado, relegando aqueles não imediatamente rentáveis (AULER, 2002, p. 2).
\end{abstract}

Para questões mais tecnocientíficas - a exemplo do debate sobre agrotóxicos, o discurso foi pronunciadamente tecnocrático (HABERMAS, 1980), enquanto quando mais próximo a princípios éticos - ética tecnológica - o modelo decisório proposto se aproxima de princípios democráticos e inclusivos. Manifestações discursivas emergentes quando da abordagem da temática ética tecnológica, apesar de entenderem a possibilidade de participação social, dão ênfase à voz do especialista: 
Quadro 10 - Excerto de corpus de análise

\begin{tabular}{l|l} 
[RC-40] & $\begin{array}{l}\text { as decisões deveriam ser tomadas pelos especialistas (pesquisadores das } \\
\text { universidades públicas e privadas); e também pela sociedade visto que a população } \\
\text { é que será diretamente atingida com a liberação ou não dos agrotóxicos. }\end{array}$
\end{tabular}

Fonte: Atividades e interações via Plataforma Moodle no contexto do curso

Anuncia-se esta distinção em [RC-81], ao contrário do discurso sobre controvérsias mais próximas à ética de [DT-4], portanto, mais afeito à opinião pública:

Quadro 11 - Excerto de corpus de análise

\begin{tabular}{|c|l|}
\hline [RC-81] & $\begin{array}{l}\text { a liberação de determinado agrotóxico deve ser acompanhada de uma série de } \\
\text { especialistas na tomada de decisão. }\end{array}$ \\
\hline [DT-4] & $\begin{array}{l}\text { todos [devem decidir sobre um padrão de conduta para algoritmos de } \\
\text { programação] já que todos os seres humanos sofrerão seus impactos, deveria ser } \\
\text { uma decisão democrática. }\end{array}$ \\
\hline
\end{tabular}

Fonte: Atividades e interações via Plataforma Moodle no contexto do curso.

O modelo tecnocrático (HABERMAS, 1980) é aquele segundo o qual o poder do especialista nas ciências é enfatizado. O caráter histórico e social do conhecimento científico é desprezado segundo esse modelo, relegando ao especialista a decisão sobre a adoção de determinada tecnologia em detrimento de outra.

Ancorada na neutralidade do aparato tecnológico - que garante a possibilidade de uma escolha objetiva e unívoca, pautada pelo critério de eficácia técnica - , tal modelo recorre ao especialista como bastião de neutralidade que irá salvaguardar o interesse público das garras do interesse do capital de forma cognitivamente qualificada, conforme [DT-7]:

Quadro 12 - Excerto de corpus de análise

\begin{tabular}{|c|l|}
\hline [DT-7] & $\begin{array}{l}\text { Sem dúvidas, com o avanço da tecnologia estamos cada vez mais próximos da } \\
\text { "Era do Futuro" idealizada e apresentada em muitos filmes de ficção científica. } \\
\text { Como a indústria e os empresários buscam cada vez mais o lucro é importante que } \\
\text { os especialistas participem do processo decisório [...] para oferecer um equilíbrio } \\
\text { na tomada de decisão e não deixar todo o poder com os empresários e produtores. }\end{array}$ \\
\hline
\end{tabular}

Fonte: Atividades e interações via Plataforma Moodle no contexto do curso

Se [DT-7] apresenta um modelo intermediário, que poderia se aproximar do modelo decisionista, esta possibilidade não se confirma, porquanto a pauta das decisões, a despeito da participação do especialista, permanece sendo a lógica privada do empresariado, e não a lógica pública do interesse coletivo, o que nos permite associar [DT-7] mais ao paradigma tecnocrata que os demais propostos por Habermas (1980). Para Pacey (1990), a perspectiva tecnocrática sufoca a democracia nas decisões relativas à tecnologia. Tal manobra se funda em uma visão de progresso, de resolução de problemas e não abarca ambiguidades:

A intolerância frente a ambiguidades inviabiliza o debate sobre o futuro: só há uma forma de avançar e o especialista, melhor do que ninguém, pode comandar o processo. A participação pública, na escolha, entre enfrentamentos possíveis a uma determinada 
situação, introduz, segundo a perspectiva tecnocrática, um elemento de incerteza, inaceitável nessa visão (PACEY, 1990, apud AULER, 2002, p. 103).

Este ideal de progresso é uma alcunha da modernidade, já identificada pelos críticos da Escola de Frankfurt, da qual o próprio Habermas é tributário. Tal progresso é frequentemente associado ao progresso material e constitui-se na meta do projeto civilizatório moderno, para o qual o progresso constitui-se na capacidade de promover e absorver progresso técnico, que por sua vez é subsidiado pela ciência. Por fim, a hegemonia da concepção tecnocrática aponta para a prerrogativa de verdades científicas que descrevem uma realidade objetiva através de um método privilegiado, o que viabiliza possibilidades tecnológicas específicas, orientadas para gerar bem-estar social.

Mitcham (1997) argumenta, contra o modelo tecnocrático, que especialistas sofrem influências, além de tenderem a promover seus próprios interesses. Continua pontuando que decisões tecnocientíficas não são neutras, além do que, conforme reconhece o supracitado [RC40], a sociedade, como diretamente afetada pelas decisões técnicas, deveriam poder se manifestar a respeito, o que coaduna com um ponto de vista filosófico sobre a autonomia moral que possuímos nestes assuntos (MITCHAM, 1997). De um ponto de vista pragmático (HABERMAS 1980), a participação pública leva a melhores resultados, e tem por corolário a formação cidadã na concepção da educação pela participação. Finalmente, Mitcham (1997) recorre ao argumento da preservação da diversidade ética e cultural pós-moderna, ameaçada pelos imperativos tecnocientíficos homogeneizantes, o que requer um consenso democráticoparticipativo.

Fiorino (1990), citado por García e colaboradores (2003, p. 134), alude ainda ao argumento normativo para o qual a "orientação tecnocrática é incompatível com os ideais democráticos. Os cidadãos são os melhores juízes e defensores de seus próprios interesses"2. $\mathrm{O}$ argumento normativo remete aos fundamentos da participação democrática do cidadão, que deve estar apto a participar da tomada de decisões que afetem a si ou a sua comunidade. Traz ainda o argumento substantivo, segundo o qual:

[...] os juízos dos leigos são tão válidos quanto os dos especialistas. Os leigos, especialmente aqueles que possuem um conhecimento familiar do entorno em que vivem, objeto de intervenção, vislumbram problemas, questões e soluções que os especialistas esquecem, desconhecem ou desconsideram como realidade local. Estudos sobre os juízos dos leigos com relação aos riscos tecnológicos revelam uma sensibilidade aos valores sociais e políticos que os modelos teóricos dos especialistas não reconhecem (GARCÍA et al., 2003, p. 135).

A necessidade de repensar o modelo tecnocrático decorre da centralidade social do desenvolvimento científico, a ponto de se tornar imperativa a busca por formas de participação social e educação científica que amparem a democratização deste modelo.

\footnotetext{
2 Irwin e Michael (2003) discutem o ideal de buscar visões leigas como constituindo uma nova ortodoxia na governança da ciência e tecnologia. Moore (2010, p. 793, tradução nossa) também acusa os entusiastas do engajamento público de aderir a esta ortodoxia emergente, baseada expressamente no argumento de que "o técnico é político, o político deve ser democrático e o democrático deve ser participativo". A isto, acadêmicos começaram a colocar o diálogo público como um bem em si (CHILVERS, 2009). Tais discussões apontam para novos paradigmas e formas de governança baseadas na responsabilidade, como é o caso da inovação responsável (von SCHOMBERG, 2011; STILGOE et al, 2013).
} 
Finalmente, com relação a princípios éticos, estes devem reger a participação social na tomada de decisão em assuntos de C\&T. Esta vinculação não surge de forma homogênea, pois temáticas de determinada natureza teriam menor participação social enquanto outras, maior. É o caso do exposto com relação à Ética Tecnológica, objeto do Eixo Desenvolvimento Tecnológico - DT. Nele os cursistas eram solicitados a discorrer acerca de quem deveria decidir sobre um padrão de conduta para algoritmos de programação de carros autônomos. No discurso, surgiram as manifestações:

Quadro 13 - Excerto de corpus de análise

\begin{tabular}{|c|l|}
\hline [DT-4] & $\begin{array}{l}\text { todos [devem decidir sobre um padrão de conduta para algoritmos de } \\
\text { programação] já que todos os seres humanos sofrerão seus impactos, deveria ser } \\
\text { uma decisão democrática }\end{array}$ \\
\hline [DT-12] & $\begin{array}{l}\text { É bem complicado, pois quem o programará colocará seu ponto de vista e se quem } \\
\text { o fizer achar que a máquina deve decidir salvar sempre os mais ricos, mais novos } \\
\text { ou de uma raça específica? Acredito que a decisão da máquina será reflexo do } \\
\text { programador. Acredito que não há uma pessoa correta, mas que deve ser discutido } \\
\text { entre inúmeras pessoas, pois cada qual tem seu ponto de vista e "estatisticamente" } \\
\text { a máquina tomará sua decisão. }\end{array}$ \\
\hline
\end{tabular}

Fonte: Atividades e interações via Plataforma Moodle no contexto do curso.

Reforçando um modelo tecnocrata sustentado seletivamente, o discurso revela que, na percepção dos cursistas, algumas controvérsias merecem mais participação social que outras, indicando uma crença na neutralidade da C\&T para temas mais técnicos.

A despeito desta manifestação, uma interpretação holística permite entender que há uma compreensão segundo a qual as mudanças decorrentes da atividade científico-tecnológica constituem um assunto público relevante, cuja importância deve ser acompanhada pela construção de bases educativas para uma participação social consciente.

\section{Considerações Finais}

Os elementos discursivos emergentes no discurso dos licenciandos em ciências não revelaram o completo abandono da perspectiva tecnocrática, sobretudo para a controvérsia dos agrotóxicos - percebida como mais técnica, ou seja, cujo posicionamento demandava maior compreensão de aspectos científicos. Outra limitação evidenciada foi a respeito do questionamento sobre a possibilidade de fundamentar juízos e decidir sobre controvérsias científicas unicamente com base em evidências empíricas, algo que ficou latente na discussão sobre Agrotóxicos realizada no Eixo Racionalidade Científica, revelando, portanto, uma atinência ao ideal de desvelamento da realidade objetiva realizado pela ciência que levaria univocamente a uma resposta sobre seu emprego e apropriação.

Evidenciou-se dois pontos subjacentes ao modelo decisório: a compreensão da participação de outros fatores além dos cognitivo-epistêmicos na construção da atividade tecnocientífica e o reconhecimento das limitações apresentadas pelo método científico para descrever a integralidade do fenômeno da C\&T.

Neste contexto, considerando o público-alvo de nossa pesquisa, retomamos a importância da formação docente como meio e como fim em si. Destacamos a fala de Gatti (2010, p. 1375), para quem é inadequado pensar a formação de professores a partir das ciências e seus diversos campos disciplinares, devendo a repensar "a partir da função social própria à 
escolarização - ensinar às novas gerações o conhecimento acumulado e consolidar valores e práticas coerentes com nossa vida civil". Daí a relevância de discutir, sobretudo nas ciências duras, questões sociais, políticas e epistemológicas.

Compreendemos que os objetivos de uma educação para democratização da ciência não representam apenas uma mudança curricular para a formação científica. Essa é necessária, mas insuficiente sem uma transformação de todas as estruturas educacionais existentes para que possam incorporar esse valor ético e político como central. Somente assim a educação, por meio da formação de cidadãos críticos e politicamente engajados, poderá dar uma resposta à altura do que exigem os desafios contemporâneos.

A temática de formação inicial de professores em conjunto com a abordagem de controvérsias científicas e modelos decisórios para fechamento de controvérsias carece de investigações futuras, que permitam maior generalização e que sanem a questão da influência das crenças dos docentes sobre as imagens transmitidas sobre as relações entre ciência, tecnologia e sociedade, bem como a influência das perspectivas sobre a docência e função do ensino de ciência nos processos e práticas educativas desenvolvidas por estes docentes.

Por fim, a relevância de nosso trabalho reside na tradição disciplinar contra a qual tentamos nos colocar. Essa é entendida não apenas em um viés cultural como também dos próprios limites do conhecimento, portanto, epistemológico. Ela é marca de nossa identidade docente e resulta que professores em formação se identifiquem mais com sua área específica de conhecimento que com as demandas escolares, e tem por corolário a resistência a propostas de práticas educativas e curriculares de natureza interdisciplinar. Tal resistência deve ser vencida para que avancemos na construção de uma educação científica emancipadora, que prepare na perspectiva humanística para o exercício da cidadania e participação social qualificada.

\section{Financiamento e agradecimentos}

Esta pesquisa foi parcialmente financiada com recursos da Fundação de Amparo à Pesquisa do Estado de Goiás - FAPEG. Agradecemos ainda as valiosas contribuições de dois revisores anônimos da presente revista.

\section{Referências}

ASSOCIAÇÃO BRASILEIRA DE SAÚDE COLETIVA. Dossiê ABRASCO. Rio de Janeiro: Abrasco, 2012.

AULER, D. Interações entre Ciência-Tecnologia-Sociedade no contexto da formação de professores de Ciências. 2002. Tese (Doutorado em Educação: Ensino de Ciências Naturais) - Universidade Federal de Santa Catarina, Santa Catarina, 2002.

BLOOR, D. Knowledge and Social Imagery. Chicago: University of Chicago Press, 1991.

BRAUN, D. Lasting tensions in research policy-making: a delegation problem, Science and Public Policy, v. 30, n. 5, p. 309-321, 2003.

BREWER, G. Politicians, Bureaucrats and the Consultant. New York: Basic Books, 1973. 
BULLA, M. E.; MEGLHIORATTI, F. A. Controvérsias científicas na construção do conhecimento biológico: investigando um curso de formação continuada de professores sobre evolução biológica humana. Investigações em Ensino de Ciências, v. 21, n. 2, p. 1-29, 2016.

CACHAPUZ, A.; GIL-PEREZ, D.; CARVALHO, A. M.; PRAIA, J.; VILCHES. (org.). A necessária renovação do ensino de ciências. São Paulo: Cortez, 2005.

CENTRO DE GESTÃo E ESTUDOS ESTRATÉGICOS. Percepção pública da C\&T no Brasil - 2019. Resumo executivo. Brasília, DF: 2019.

CHILVERS, J. Deliberative and participatory approaches in environmental geography. In: CASTREE, N. et al. (org.), The Companion to Environmental Geography. London: Blackwell, 2009.

COLLINS, H. M. Stages in the empirical programme of relativism. Social Studies of Science, v. 11, n. 1, p. 3-10, 1981.

COLLINS, H. M. Mudando a ordem: reprodução e indução na prática científica. Belo Horizonte: Fabrefactum Editora, 2011.

COLLINS, H. M. The Sociology of Scientific Knowledge: studies of contemporary science. Annual Review of Sociology, n. 9, p. 265-285, 1983.

COLLINS, H. M; EVANS, R. Repensando a Expertise. Belo Horizonte: Fabrefactum Editora, 2009.

COZZENS, S.; WOODHOUSE, E. Science, Government and the politics of knowledge. In: JASANOFF, S. et al. (org.) Handbook of science and technology studies. London: Sage, 1995.

DUARTE, T. R. O Programa Forte e a Busca de uma Explicação Sociológica das Teorias Científicas: Constituição, Propostas e Impasses. 2007. Dissertação (Mestrado em Sociologia) - Universidade Federal de Minas Gerais, Minas Gerais, 2007.

ELZINGA, A.; JAMILSON, A. Changing policy agendas in science and technology. In: JASANOFF, S. et al. (org.) Handbook of science and technology studies. London: Sage, 1995.

ENGELHARDT, T. H.; CAPLAN, A. (org.). Scientific controversies: Case studies in the resolution and closure of disputes in Science and technology. New York: Cambridge University Press, 2003.

GALVÃO, C.; REIS, P.; FREIRE, S. A discussão de controvérsias sociocientíficas na formação de professores. Ciência \& Educação (Bauru), v. 17, n. 3, p. 505-522, 2011.

GARCÍA E. M. P. et al. Introdução aos estudos CTS (Ciência, Tecnologia e Sociedade). Madrid: OEI, 2003.

GATTI, B. A. Formação de professores no Brasil: características e problemas. Educação \& Sociedade (Campinas), v. 31, n. 113, p. 1355-1379, Dec. 2010. 
GIERE, R. Controversies involving Science and technology: a theoretical perspective. In: ENGELHARDT, T.; CAPLAN, A. (org.) Scientific controversies: Case studies in the resolution and closure of disputes in Science and technology. New York: Cambridge University Press, 2003.

GONZÁLEZ, M. I. G.; LÓPEZ, J. A.C.; LUJÁN, J. L. Ciencia, tecnología y sociedad. Una introducción al estudio social de la ciencia y la tecnología. Madrid: Tecnos, 1996.

GOODELL, R. The role of the mass media in scientific controversy. In: ENGELHARDT, T.; CAPLAN, A. Scientific controversies: Case studies in the resolution and closure of disputes in Science and technology. New York: Cambridge University Press, 2003.

HABERMAS, J. Técnica e ciência enquanto ideologia. São Paulo: Abril Cultural, 1980.

HORKHEIMER, M. Eclipse da razão. São Paulo: Centauro, 2002.

IRWIN, A.; MICHAEL, M. Science, Social Theory and Public Knowledge. Philadelphia: Open University Press, 2003.

JASANOFF, S. Contested Boundaries in Policy-Relevant Science. Social Studies of Science, n. 17, v. 2, p. 195-230, 1987.

JASANOFF, S. Ordering Knowledge, Ordering Society. In: JASANOFF, S. (org.) States of Knowledge: The Co-Production of Science and Social Order. London: Routledge, 2004.

JASANOFF, S. Science and Democracy. In: FELT, U. et al. (org.) The handbook of science and technology studies. Massachusetts: The MIT Press, 2017.

JASANOFF, S. Technologies of humility: citizen participation in governing science.

Minerva, v. 41 n. 3, p. 223-244, 2003.

KNELLER, G. F. A Ciência como Atividade Humana. Rio de Janeiro: Zahar Editores, 1980.

LATOUR, B.; WOOLGAR, S. A vida de laboratório: a produção de fatos científicos. Rio de Janeiro: Editora Relume Dumará, 1997.

MITCHAM, C. Justifying public participation in technical decision making. IEEE

Technology and Society Magazine, v. 16, n. 1, p. 40-46, 1997.

MOORE, A. Beyond participation: opening up political theory in STS. Social Studies of Science, v. 40, n. 5, p. 793-799, 2010.

MORAES, R.; GALIAZZI, M. C. Análise Textual Discursiva. 2. ed. Ijuí: Editora Unijuí, 2011.

NASCIMENTO, F.; FERNANDES, H. L.; MENDONÇA, V. M. O ensino de ciências no Brasil: história, formação de professores e desafios atuais. Revista HISTEDBR On-line, [S.1.], v. 10, n. 39, p. 225-249. 2012. 
NELKIN, D. The Political Impact of Technical Expertise. Social Studies of Science, v. 5, n. 1, p. 35-54, 1975.

RAICIK, A. C.; PEDUZZI, L. O. Q.; ANGOTTI, J. A. P. A estrutura conceitual e epistemológica de uma controvérsia científica: implicações para o ensino de ciências. Experiências Em Ensino De Ciências, v. 13, p. 42-62, 2018.

SANTOS, M. Por uma outra Globalização: do pensamento único à consciência universal. 3. ed. Rio de Janeiro: Record, 2000.

SANTOS, W. L. P. Educação científica na perspectiva de letramento como prática social: funções, princípios e desafios. Revista Brasileira de Educação, v. 12, n. 36, 2007.

SANTOS, W. L. P.; MORTIMER, E. F. Tomada de Decisão para Ação Social Responsável no Ensino de Ciências. Ciência \& Educação, v.7, n.1, p.95-111, 2001.

SANTOS, W. L. P.; MORTIMER, E. F. Uma Análise de Pressupostos Teóricos da Abordagem CT-S (Ciência - Tecnologia - Sociedade) no contexto da educação brasileira. Ensaio - Pesquisa em Educação em Ciências. v. 2, n. 2, 2002.

SANTOS, W. L. P.; SCHNETZLER, R. P.; Educação em Química: compromisso com a cidadania. Ijuí: Editora Unijuí, 2014.

SAREWITZ, D. Salvar la Ciencia. Revista de Economia Institucional, v.19, n.37, p.31-65, 2017.

SHAPIN, S. Here and Everywhere: Sociology of Scientific Knowledge. Annual Review of Sociology, v. 21, p. 289-321, 1995.

SOUSA, R. S.; GALIAZZI, M. C. O jogo da compreensão na análise textual discursiva em pesquisas na educação em ciências: revisitando quebra-cabeças e mosaicos. Ciência \& Educação (Bauru), v. 24, n. 3, p. 799-814, 2018.

STILGOE, J.; OWEN R.; MACNAGHTEN P. Developing a framework for responsible innovation. Research Policy, v. 42, n. 9, p. 1568-1580, 2013.

VOGT, C. A. A espiral da cultura científica. ComCiência, Campinas, v. 45, 2003.

von SCHOMBERG, R. Prospects for technology assessment in a framework of responsible research and innovation. In: DUSSELDORP, M.; BEECROFT, R. (org.), Technikfolgen Abschätzen Lehren: Bildungspotenziale Transdisziplinärer. Heidelberg: Springer VS, 2011.

ZEIDLER, D. et al. Beyond STS: A research-based framework for socioscientific issues education. Science Education, v. 89, n.3, p 357-377, 2005.

Recebido em março de 2020.

Aprovado em maio de 2020. 